\title{
Tailoring the mechanical properties of 3D-designed poly(glycerol sebacate) scaffolds for cartilage applications
}

\author{
Jessica M. Kemppainen, ${ }^{1}$ Scott J. Hollister ${ }^{1,2,3}$ \\ ${ }^{1}$ Department of Biomedical Engineering, University of Michigan, Ann Arbor, Michigan 48109-2125 \\ ${ }^{2}$ Department of Mechanical Engineering, University of Michigan, Ann Arbor, Michigan 48109-2125 \\ ${ }^{3}$ Department of Surgery, The University of Michigan, Ann Arbor, Michigan 48109-0329
}

Received 14 March 2009; revised 5 June 2009; accepted 9 July 2009

Published online 20 January 2010 in Wiley InterScience (www.interscience.wiley.com). DOI: 10.1002/jbm.a.32653

\begin{abstract}
Matching tissue engineering scaffold modulus to that of native tissue is highly desirable. Effective scaffold modulus can be altered through changes in base material modulus and/or scaffold pore architecture. Because the latter may be restricted by tissue in-growth requirements, it is advantageous to be able to alter the base material modulus of a chosen scaffold material. Here, we show that the bulk modulus of poly(glycerol sebacate) (PGS) can be changed by varying molar ratios during prepolymer synthesis and by varying curing time. We go on to show that PGS can be used to create 3D designed scaffolds via solid freeform fabrication methods with modulus values that fall within the
\end{abstract}

ranges of native articular cartilage equilibrium modulus. Furthermore, using base material modulus inputs, homogenization finite element analysis can effectively predict the tangent modulus of PGS scaffold designs, which provides a significant advantage for designing new cartilage regeneration scaffolds. Lastly, we demonstrate that this relatively new biomedical material supports cartilaginous matrix production by chondrocytes in vitro. (C) 2010 Wiley Periodicals, Inc. J Biomed Mater Res 94A: 9-18, 2010

Key words: poly(glycerol sebacate); cartilage tissue engineering; scaffolds

\section{INTRODUCTION}

Polymer scaffolds will play a key role in treating cartilage defects, deterioration, and damage caused by aging, disease, and trauma. There are a number of synthetic materials and a wide range of fabrication methods being applied to make such scaffolds, with the general acceptance that these constructs should be biocompatible, biodegradable, and mechanically stable. Here, we focus on the requirement that a scaffold should have mechanical properties, particularly tangent modulus values, in the range of native cartilage equilibrium modulus values. There are two components that determine the final effective scaffold modulus: (1) the base material modulus and (2) the scaffold pore architecture. As pore geometry may be restricted by tissue in-growth edu

Correspondence to: S. J. Hollister; e-mail: scottho@umich.

Contract grant sponsor: National Science Foundation (GSRF), a Regenerative Sciences Training Grant; contract grant number: T90 DK070071

Contract grant sponsor: NIH; contract grant number: RO1 DE 13608

(C) 2010 Wiley Periodicals, Inc. requirements, it would be advantageous to be able to alter effective scaffold modulus simply by altering the base material modulus. We show how the processing conditions of poly(glycerol sebacate) (PGS) can be varied to tailor the mechanical properties of three-dimensionally designed, solid-freeform fabricated (SFF) scaffolds for cartilage tissue engineering.

Poly(glycerol sebacate) has been recently developed for tissue engineering. ${ }^{1-13}$ Synthesis and characterization of the polymer, created through a polycondensation reaction of glycerol and sebacic acid, was first reported for use in biotechnology and bioengineering in $2002^{1}$ to provide good mechanical properties and rubber-like elasticity, established degradation and crosslinking mechanisms optimal for soft tissue engineering applications. Along with being tougher, less expensive and more flexible than existing biodegradable elastomers, glycerol is a humectant used in foods and beverages, and polymers containing sebacic acid (e.g., Polifeprosan) have been approved by the US Food and Drug Administration for drug delivery applications. To date, PGS has been studied for applications in nerve guidance, ${ }^{2}$ soft tissue regeneration, ${ }^{3,4}$ vascular and myocardial tissue regeneration, ${ }^{5-9}$ blood vessel reconstruction, ${ }^{10,11}$ drug delivery, ${ }^{12}$ and replacement of photo- 
receptor cells. ${ }^{13}$ PGS is a biodegradable polymer with biocompatibility and mechanical properties that make it well suited for applications such as those mentioned and, as we show here, for use in cartilage tissue engineering.

PGS is processed by creating a prepolymer, and then curing the prepolymer at high temperatures to obtain a thermoset elastomeric polymer. Most studies have fabricated the polymer through conventional methods, creating films or porogen-leached sponges. The most advanced structures reported are tubular sheets and films developed as scaffolds for blood vessels, renal tubules or various ducts. ${ }^{10,11}$ In this work, we demonstrate the ability to process PGS using SFF techniques to create scaffolds with designed pore shapes, pore sizes, porosities, and architectures. In the past, this fabrication has been widely used in our lab ${ }^{14-23}$ to make designed scaffolds from poly(L-lactic acid), poly(lactic-co-glycolic acid), poly( $\varepsilon$-caprolactone), hydroxyapatite, poly(propylene-fumarate), and poly(propylene-fumarate)/tricalcium phosphate blends for applications in bone regeneration, spinal cord reconstruction, and cartilage tissue engineering. Because most of these materials, when fabricated into three-dimensional (3D) designed scaffolds, exhibit mechanical properties that are outside the ranges of cartilage, we have more recently applied this technology to more elastomeric materials, such as poly(glycerol sebacate) (PGS) and poly(1,8-octanedial-co-citrate) (POC) for cartilage tissue engineering applications. ${ }^{24}$ We believe that the mechanical properties of these materials make them ideal for use in fabricating scaffolds for load bearing articular sites. Fabrication of PGS by this means is not yet reported.

One of the main advantages of using PGS for tissue engineering is that its mechanical properties can be tailored to match specific tissue properties through altering processing parameters during the prepolymer and/or curing steps. In 2008, Chen et al. ${ }^{7}$ demonstrated the ability to alter the mechanical properties of PGS for myocardial tissue applications through changing curing temperature, recording Young's modulus values of $0.056 \mathrm{MPa}$ $\left(110^{\circ} \mathrm{C}\right), 0.22 \mathrm{MPa}\left(120^{\circ} \mathrm{C}\right)$, and $1.2 \mathrm{MPa}\left(130^{\circ} \mathrm{C}\right)$. In this work, we evaluate how changing the molar ratios of glycerol:sebacic acid during prepolymer synthesis and how changing the curing time causes variations in nonlinear elastic mechanical properties.

The purpose of this work is to assess PGS as a scaffolding material for cartilage tissue engineering by determining how synthesis conditions affect both bulk PGS properties and PGS scaffolds with designed architecture. As the use of PGS for cartilage regeneration has not yet been reported, we further demonstrate that PGS scaffolds support robust cartilage formation when seeded with porcine chondrocytes in vitro.

\section{MATERIALS AND METHODS}

\section{Fabrication of PGS solid cylinders and 3D-designed scaffolds}

Prepolymer synthesis

PGS prepolymer (pPGS) was synthesized following methods described by Gao et al. ${ }^{4}$ Three batches of pPGS were synthesized with various molar ratios of sebacic acid:glycerol (3:4, 1:1, and 4:3). Sebacic acid and glycerol were reacted under $\mathrm{N}_{2}$ at $120^{\circ} \mathrm{C}$. After $24 \mathrm{~h}$, the $\mathrm{N}_{2}$ was removed and a vacuum of 50 mTorr was pulled for an additional $48 \mathrm{~h}$, with a condenser attached.

\section{Polymer curing}

Prepolymer was cured through a modified protocol $^{4}$ that enabled fabrication of designed architecture scaffolds from wax molds. To create solid cylinders for mechanical testing, the prepolymer was poured into a Teflon mold and cured at $150^{\circ} \mathrm{C}$ for various time points $(24 \mathrm{~h} \mathrm{w} /$ out vacuum plus 24,48 , or $72 \mathrm{~h}$ with a 100 mTorr vacuum). A 3D scaffold ( $3 \mathrm{~mm}$ height, $6.35 \mathrm{~mm}$ diameter, $1 \mathrm{~mm}$ spherical pores, and $54 \%$ porosity) was designed using custom Interactive Data Language ${ }^{\mathrm{TM}}$ programs (IDL; Research Systems, Boulder, CO). ${ }^{15,16}$ To fabricate designed scaffolds, wax molds of the final scaffold design were made on a Solidscape printer (Solidscape, Merrimack, NH). Wax molds were pressed into hydroxyapatite (HA) following a protocol previously established in the lab, ${ }^{24}$ resulting in an inverse HA mold. The inverse HA mold was pressed into pPGS that had been poured into a Teflon mold. ${ }^{25}$ The Teflon/pPGS/HA mold unit was placed within a vacuum oven to cure at $150^{\circ} \mathrm{C}$. For the first $24 \mathrm{~h}$, no vacuum was pulled, to allow the prepolymer to begin to cure, preventing air bubbles from forming in the polymer when a vacuum is pulled. After $24 \mathrm{~h}$, a strong vacuum (100 mTorr) was pulled, and the temperature was maintained at $150^{\circ} \mathrm{C}$ for 24,48 , or $72 \mathrm{~h}$ longer. The HA+PGS construct was removed from the cup, and the HA was dissolved out using a rapid decalcifying agent (RDO, Apex Engineering, Aurora, IL) to achieve the final PGS scaffold. The schematic of this process is shown in Figure 1. PGS scaffolds and cylinders were autoclaved and rinsed overnight in DMEM before mechanical testing or chondrocyte seeding. Cylinder and scaffold diameters were measured before and after rinsing in DMEM. Note, curing times reported in the results section refer to the hours cured after a vacuum was pulled (24, 48 , and $72 \mathrm{~h})$.

\section{Fabrication of 3D-designed PCL control scaffolds}

For in vitro testing experiments, control 3D polycaprolactone (PCL) scaffolds were made using the design previously described for PGS scaffolds $(3 \mathrm{~mm}$ height, $6.35 \mathrm{~mm}$ 


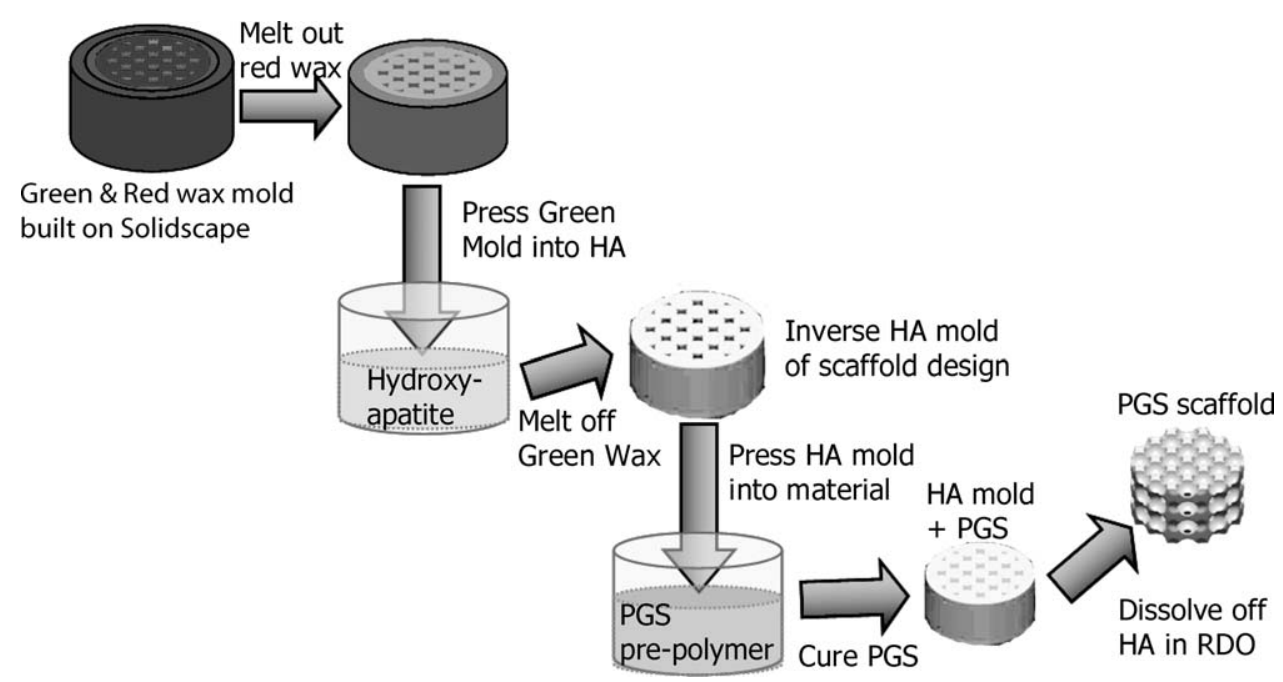

Figure 1. Fabrication of 3D designed PGS scaffolds involves first creating wax molds, which are cast into hydroxyapatite to create an inverse mold, which is then cast into PGS prepolymer and cured, resulting in a PGS scaffold.

diameter, $1 \mathrm{~mm}$ spherical pores, and $54 \%$ porosity). PCL scaffolds were made by pressing these wax molds directly into melted $37 \mathrm{kDa}$ polycaprolactone (CAPA 6400, Solvay Caprolactones, Warrington, Cheshire, UK). Briefly, PCL pellets were placed into a Teflon mold and melted $\left(115^{\circ} \mathrm{C}\right.$, 1 Torr, $120 \mathrm{~min})$. After melting and air bubble removal, the Teflon mold was pulled from the oven and allowed to cool for $270 \mathrm{~s}$ at room temperature, reaching $80^{\circ} \mathrm{C}$ (just below the melting temperature of the wax molds). At this time, inverse wax molds were pressed into the melted PCL, and the entire construct was cooled overnight. Wax was dissolved from the PCL using 100\% EtOH.

\section{Microcomputed tomography image analysis}

To assess defects and create images for finite element analysis (FEA), solid cylinders and scaffolds were scanned using a MS-130 high resolution (CT scanner (GE Medical Systems, Toronto, CAN) at a $16-\mu \mathrm{m}$ voxel resolution. Scans were performed in air at $75 \mathrm{kV}$ and $75 \mathrm{~mA}$. GEMS Microview software (GE Medical Systems, Toronto, CAN) was used to view reconstructed images.

\section{Mechanical testing}

Solid PGS cylinders and PGS 3D-designed scaffolds were tested in compression using an MTS Alliance RT30 electromechanical test frame (MTS Systems Corp., MN).

\section{Stress-relaxation in confined compression}

Stress-relaxation tests were performed in confined compression following a protocol established by Guilak et al. ${ }^{26}$ and used extensively in the field by others. ${ }^{27,28}$ Briefly, presoaked samples were loaded into a confining cylindrical chamber filled with a phosphate-buffered saline solution controlled at $37^{\circ} \mathrm{C}$. A porous indenter was lowered until a reading of $0.22 \mathrm{~N}$ was output on the computer, signifying that the indenter was in contact with the cylinder or scaffold. This load was held for $600 \mathrm{~s}$ and assumed to be the $0 \%$ strain position. Under displacement control, stress-relaxation testing was performed with a single ramp of $20 \%$ strain applied at $0.25 \mu \mathrm{m} / \mathrm{s}$ or $5 \mu \mathrm{m} / \mathrm{min}$. The crosshead was then held at constant displacement for $30 \mathrm{~min}$ to record relaxation.

\section{Unconfined compression}

Unconfined compression tests were performed on solid cylinders ( $n=5-10$ for each group, with variation in sample size due to exclusion of cylinders with defects) under displacement control. Samples were compressed to failure in the $z$-direction between two fixed steel platens at a rate of $2 \mathrm{~mm} / \mathrm{min}$ after a preload of $0.05 \mathrm{lb}$ was applied. A single set of $3 \mathrm{D}$-designed scaffolds were fabricated $(n=7)$ (1:1 molar ratio, $48 \mathrm{~h}$ cure time) and tested in unconfined compression to validate FEA predictions.

\section{Finite element analysis}

Complete anisotropic effective stiffness constants were calculated using the voxel-based homogenization software VOXELCON (Quint Corp, Tokyo, Japan), as described previously. $^{23}$ STL design files were converted to .vox files, and PGS modulus values from mechanical testing of solid cylinders ( 3 molar ratios $\times 3$ curing times) were input into VOXELCON, with a Poisson's ratio of 0.3 and run on scaffold designs.

\section{In vitro study}

\section{Chondrocyte harvest}

Cartilage was harvested from fresh metacarpophalangeal joints of domestic pigs obtained from a local abattoir 
(Northwest Market, Northwest, MI). Cartilage pieces were digested in a digest solution [DMEM high glucose, serum free, $1 \mathrm{mg} / \mathrm{mL}$ collagenase II (Sigma No. C1764), 2\% Pen/ strep, 2\% kanamycin (Roche, 12728700), and 0.2\% Fungizone (Invitrogen, 15290-018)] on a stir plate for $6 \mathrm{~h}$ at $37^{\circ} \mathrm{C}$, $5 \% \mathrm{CO}_{2}$. The solution was then filtered through sterile nylon. Cells were spun at $2000 \mathrm{rpm}$ for $8 \mathrm{~min}$, and plated overnight on tissue culture polystyrene in DMEM + $10 \%$ FBS $+1 \% \mathrm{P} / \mathrm{S}+50 \mu \mathrm{g} / \mathrm{mL}$ 2-phospho-L-ascorbic acid (BioChemika, 49752). The following day, cells were trypsinized and immediately suspended in collagen gel for scaffold seeding.

\section{Cell seeding and in vitro culture}

PGS scaffolds (1:1 molar ratio, $48 \mathrm{~h}$ cure time) were sterilized in an autoclave and presoaked in DMEM for $24 \mathrm{~h}$ before cell seeding. Chondrocytes were suspended in a composite 5\% Hyaluronic Acid (HyA) (stock concentration: $2.7 \mathrm{mg} / \mathrm{mL}$ in $0.8 \mathrm{M} \mathrm{NaCl}, \mathrm{MW}: 3 \times 10^{6} \mathrm{Da}$ : Hyalogic LLC, Edwardsville, KS) info)/collagen I gel (stock concentration: $5.9 \mathrm{mg} / \mathrm{mL}$, BD Biosciences, No. 354236) at $\sim 30 \times 10^{6}$ cells $/ \mathrm{mL}$. $4 \% \mathrm{v} / \mathrm{v} 0.5 \mathrm{M}$ sodium hydroxide with $220 \mathrm{mg} / \mathrm{mL}$ sodium bicarbonate was used to increase the $\mathrm{pH}$ of the collagen/HyA/cell suspension just before seeding into the scaffolds to create gelling at $37^{\circ} \mathrm{C}$. Cells were evenly seeded into scaffolds using a custom designed Teflon mold. After gelling ( $\sim 30 \mathrm{~min})$, scaffolds were removed from the mold. Scaffold + Cells + Gel constructs were cultured in an incubator $\left(37^{\circ} \mathrm{C}, 5 \% \mathrm{CO}_{2}\right)$ in 24-well plates on an orbital shaker for 2 weeks. Media (DMEM, 10\%FBS, 1\% $\mathrm{P} / \mathrm{S}, 0.1 \mathrm{mM}$ nonessential amino acids, $50 \mu \mathrm{g} / \mathrm{mL}$ 2-phospho-L-ascorbic acid, $0.4 \mathrm{mM}$ proline, $5 \mu \mathrm{g} / \mathrm{mL}$ insulin) was changed every other day. PCL control scaffolds were seeded and cultured in the same manner.

\section{Histological staining}

After 2 weeks, PGS scaffolds $(n=2)$ were removed, fixed in $10 \%$ buffered formalin phosphate (Fisher, SF10020) overnight, dehydrated in $\mathrm{EtOH}$ washes, and paraffin embedded. Histological sectioning was performed $\sim 1500$ $\mu \mathrm{m}$ from the scaffold surface (at approximately the mid point of the scaffold) and sections were stained with Alcian Blue to illustrate GAG production.

\section{Sulfate-glycosaminoglycan (sGAG) quantification}

At 2 weeks, PGS scaffolds $(n=3)$ and control PCL scaffolds $(n=3)$ were removed from culture, finely chopped, and placed immediately into $1 \mathrm{~mL}$ of papain solution (papain, $1 \times$ PBS, cysteine HCL, EDTA, $\mathrm{pH}=6.0$; mixed for 3 $\mathrm{h}$ at $37^{\circ} \mathrm{C}$ then filtered). Scaffolds were digested in papain for $24 \mathrm{~h}$ and then immediately frozen at $-20^{\circ} \mathrm{C}$. A DMMB assay was run on digested scaffolds. Briefly, $20 \mu \mathrm{L}$ of sample was mixed with $200 \mu \mathrm{L}$ of dimethylmethylene blue reagent and absorbance was immediately read on a plate reader (MultiSkan Spectrum, Thermo, Waltham, MA) at $525 \mathrm{~nm} .{ }^{29}$ Readings were compared with a standard curve established from chondroitin 6-sulfate from shark (Sigma, C4384).

\section{DNA quantification}

Papain digested PGS scaffolds $(n=3)$ and control PCL scaffolds $(n=3)$ were also used to determine DNA content through a Hoechst 33258 Assay (Sigma, No. 861405). Briefly, $100 \mu \mathrm{L}$ digested sample was added to $100 \mu \mathrm{L}$ Hoechst and read with excitation: $355 \mathrm{~nm}$, emission: $460 \mathrm{~nm}$ (Fluoroskan Ascent FL, Thermo, Waltham, MA) in a 96-well plate. Readings were compared with standards made from calf thymus DNA (Sigma, No. D0805).

\section{Quantitative-PCR}

qtPCR was used to determine the expression of cartilage specific genes (collagen II and aggrecan), a chondrocyte dedifferentiation marker (collagen I), and a house-keeping gene (GAPDH). Scaffolds were removed from culture, rinsed twice with PBS, cut into small pieces $\left(\sim 1 \mathrm{~mm}^{3}\right)$, and placed immediately into RNAlater (Qiagen, D-40724). Scaffolds were incubated in RNAlater at $4^{\circ} \mathrm{C}$ for $24 \mathrm{~h}$ then transferred to $-20^{\circ} \mathrm{C}$ for storage. For RNA extraction, scaffold + tissue were homogenized in Buffer RLT for $\sim 60 \mathrm{~s}$. Lysate was then centrifuged, and supernatant was removed. RNA was extracted using an RNeasy Mini Kit (Qiagen No. 74104), and samples were stored at $-80^{\circ} \mathrm{C}$. After measurement of RNA concentration for each sample, first-stand cDNA was synthesized using random primers (Superscript Kit No. 18064). Samples were prepared for qtPCR using a Taqman universal PCR master mix (Applied Biosystems, 4304437) and custom designed porcine primers. qtPCR was then performed using an ABI PRISM 7700 (Applied Biosystems, Foster City, CA). As a control, before seeding, $5 \times 10^{6}$ chondrocytes were incubated in RNAlater and used for qtPCR.

\section{Statistical analysis}

Multiple linear regression was performed using SPSS software (SPSS for Windows, Rel 14.0. 2005 Chicago: SPSS).

\section{RESULTS}

\section{Fabrication of cylinders and scaffolds}

Caliper measurements of PGS cylinder and scaffold diameters showed no significant swelling of constructs after soaking in DMEM for $24 \mathrm{~h}$ (average solid cylinder diameter before DMEM soak $=6.45$ $\mathrm{mm} \pm 0.03 \mathrm{~mm}$, after soaking $=6.46 \mathrm{~mm} \pm 0.03$ $\mathrm{mm}$; average scaffold diameter before DMEM soak = $6.43 \mathrm{~mm} \pm 0.03 \mathrm{~mm}$, after soaking $=6.44 \mathrm{~mm} \pm$ $0.02 \mathrm{~mm}$ ). Micro-CT analysis of solid cylinders confirmed the absence of air bubble defects in these 

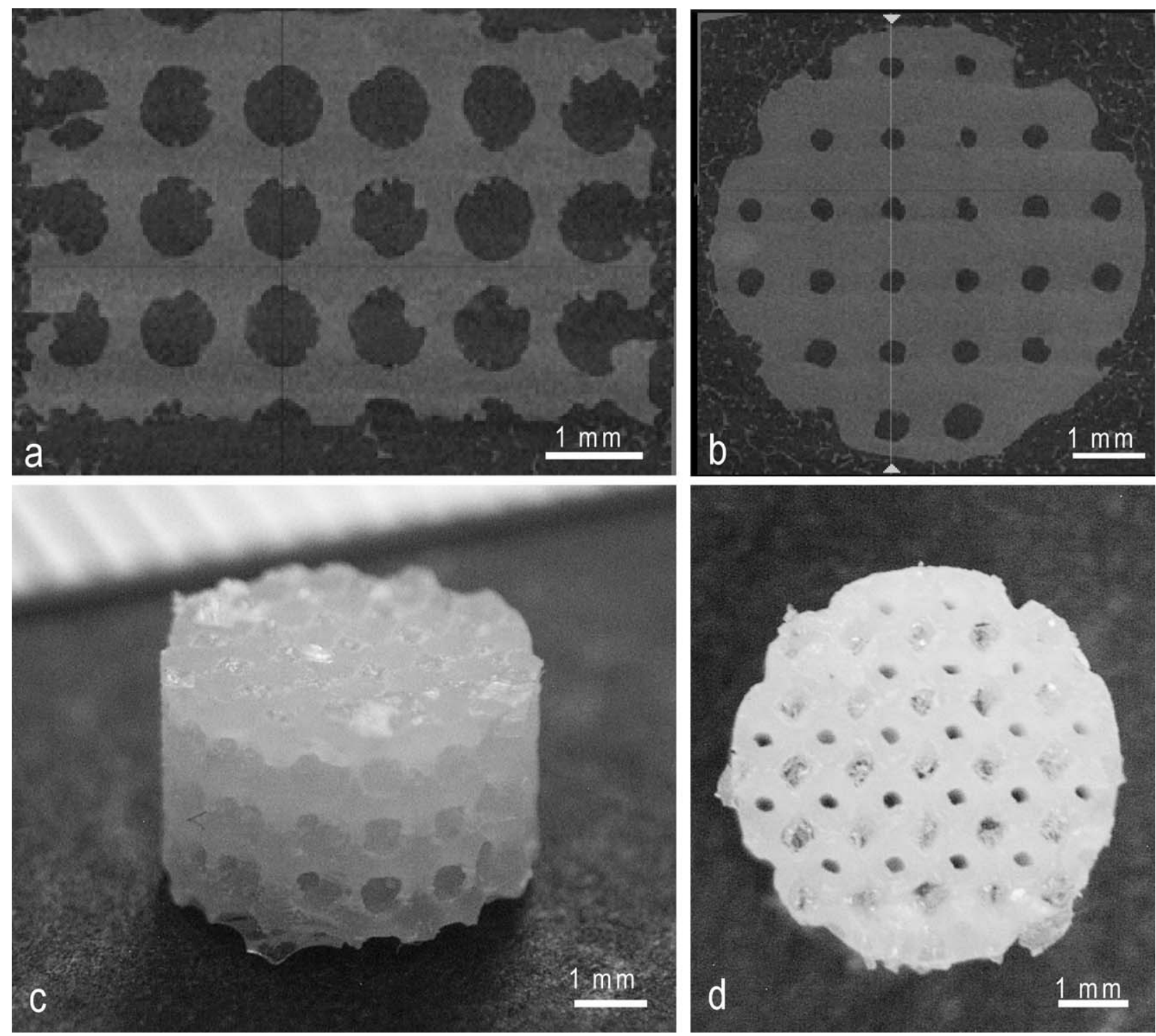

Figure 2. Successfully fabricated 3D-designed PGS scaffolds illustrated through micro-CT images, side view (a) and top view (b) and digital images, side view (c) and top view (d) show no defects.

mechanical testing specimens. Successful fabrication of designed scaffolds can be seen in Figure 2, where $\mu-\mathrm{CT}$ analysis of scaffolds, again, confirms the absence of defects [Fig. 2(a,b)]. Volume fraction quantification done on $\mu$-CT images reveals that the porosity of fabricated scaffolds $(48.1 \% \pm 4.24 \%)$ is slightly less than that of the design file $(54 \%)$, whereas scaffold pore diameters $(1.04 \mathrm{~mm} \pm 0.04 \mathrm{~mm})$ are equal to designed pore sizes $(1.0 \mathrm{~mm})$. Decreased porosity of actual scaffolds is most likely due to small amounts of PGS penetrating into pores.

\section{Mechanical property variations}

Stress-relaxation testing done on solid cylinders $(n=$ 2 for each molar ratio/cure time) revealed that PGS does not exhibit a viscoelastic response. Stress-relaxation profiles were not dependent on strain rate $(0.25$ $\mu \mathrm{m} / \mathrm{s}$ vs. $5 \mu \mathrm{m} / \mathrm{s}$ ), nor did they relax under constant displacement after loading (Fig. 3), indicating that PGS exhibited predominantly elastic properties and therefore, PGS bulk and scaffolds were tested in unconfined compression and fit to a $1 \mathrm{D}$ nonlinear elastic model commonly used for biological soft tissues:

$$
T=A\left(e^{B \varepsilon}-1\right)
$$

where $T$ is the 1st Piola-Kirchoff stress, $\varepsilon$ is the large strain, and $A$ and $B$ are model parameters fit to experimental data. The fit was performed using a specially written MATLAB program calling the optimization function fminunc. The tangent modulus at $10 \%$ strain was calculated as follows: 

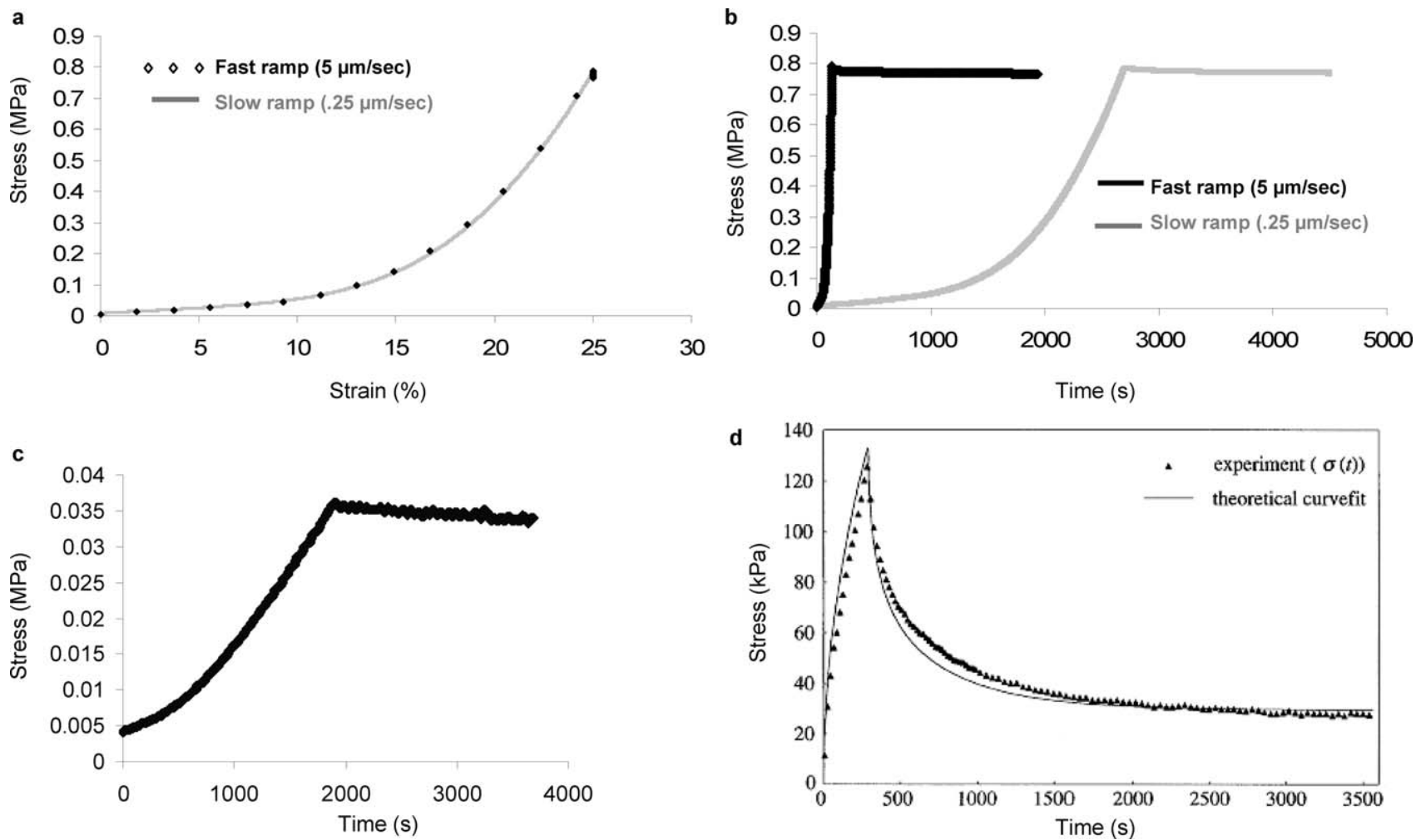

Figure 3. Evidence that PGS does not exhibit viscoelastic characteristics is illustrated when (a) the stress-strain response for solid PGS cylinders is not dependent on strain rate, (b) stress-relaxation of bulk PGS is not demonstrated during fast or slow ramping speeds, (c) there is no stress-relaxation response of a 3D PGS scaffold, when compared with (d) the viscoelastic response of cartilage shown by Soltz and Ateshian. ${ }^{27}$

$$
E^{\text {tangent }}=\frac{\mathrm{d} T}{\mathrm{~d} \varepsilon}=A B e^{B \varepsilon}
$$

Representative curve fits for solid cylinders and 3D scaffolds can be seen in Figure 4.

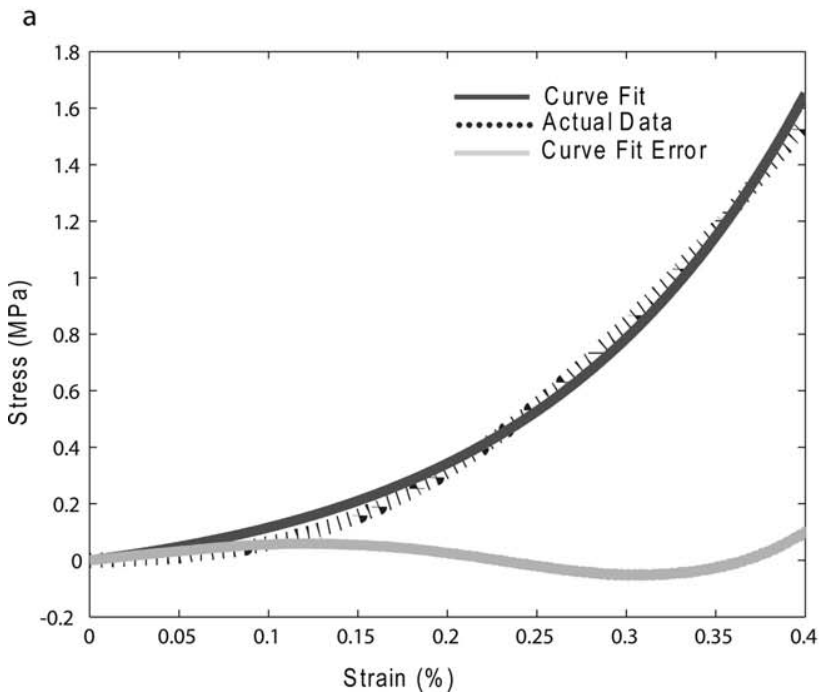

As seen in Figure 5, the tangent elastic modulus of PGS is significantly altered through variations in prepolymer molar ratios and curing times. Multiple regression provided a powerful (predictive power, adjusted $R^{2}=0.70$ ) linear equation for tangent

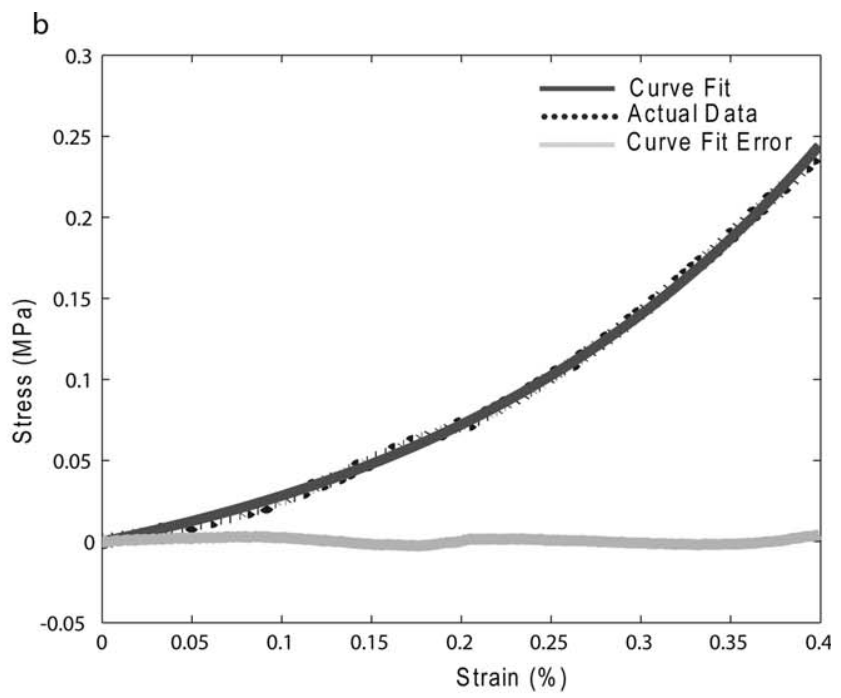

Figure 4. A 1D nonlinear elastic model provides a good fit for solid PGS cylinders (a) and 3D-designed scaffolds (b). 


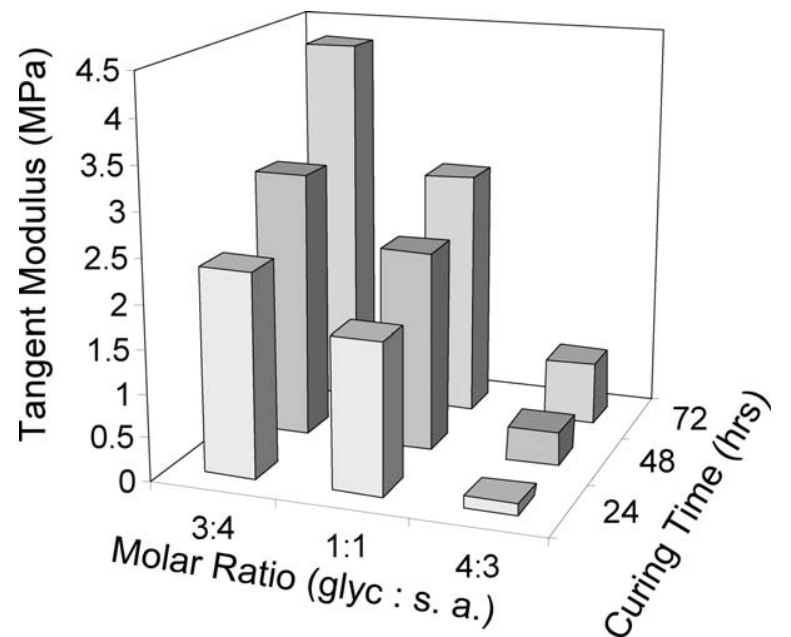

Figure 5. Tangent Modulus (at 10\% strain) values for PGS cylinders with various processing parameters. Linear regression can be used to predict the modulus $(70 \%$ power) from these two variables: Modulus $(\mathrm{MPa})=3.607-$ $1.410 *$ (ratio of glycerol:sebacic acid) $+0.60 *$ (vacuum curing time in hours).

modulus (at $10 \%$ strain) dependent on these two variables: $y=3.607-1.410 *$ (molar ratio of glycerol: sebacic acid) $+0.60 *$ (curing time in hours).

\section{Homogenization finite element analysis}

Homogenization FEA was used to calculate the tangent elastic modulus values of scaffold design files and $\mu-\mathrm{CT}$ images of actual scaffolds using values of solid cylinder tangent modulus at $10 \%$ strain. Table I displays experimental modulus values of solid cylinders, FEA predictions of modulus values for a 3D scaffold from design files, and modulus values from experimentally tested scaffolds. The voxel model is able to accurately predict the tangent modulus of scaffolds from the design file $($ prediction $=0.60 \mathrm{MPa}$, actual $=0.57 \pm 0.24$ ) .

\section{In vitro study}

Chondrocytes suspended in collagen $1 / 5 \%$ hyaluronic acid composite hydrogel within 3D designed scaffolds maintained a rounded morphology and produced a cartilaginous matrix as seen in digital images and through alcian blue staining in Figure 6. Sulfated-GAG concentrations were within the same ranges as chondrocytes cultured under identical conditions on poly(e-caprolactone) (PCL) of the same architectural design $(29.64 \pm 11.87$ vs. $33.00 \pm$ $6.24 \mu \mathrm{g}$ GAG/ $\mu \mathrm{g}$ DNA, respectively). Collagen 2: collagen 1 ratios were higher for chondrocytes cultured on PGS than those cultured under identical conditions on PCL $(20.91 \pm 3.25$ vs. $8.69 \pm 0.17)$, but were lower than mRNA expression by unseeded chondrocytes (267). Aggrecan expression by cells on PGS was similar to cells seeded on PCL $(1.74 \pm 0.68$ vs. $1.67 \pm 0.07)$, and both expression levels were higher than expressed by preseeded chondrocytes (0.37). Note: "preseeded" refers to an aliquot of cells taken immediately before seeding the batch of cells onto a scaffold.

\section{DISCUSSION AND CONCLUSIONS}

We have presented a novel PGS scaffold fabrication method. Actual scaffold pore sizes and porosities showed no major deviations from design files, and there is no significant swelling of solid cylinders or scaffolds when they are soaked in DMEM.

It is highly desirable to be able to match effective scaffold mechanical properties to native tissue properties for scaffolds designed for optimal tissue regeneration. Intuitively, one way in which the mechanical

TABLE I

Modulus Values of Solid PGS Cylinders Made from Varying Glycerol:Sebacic Acid Molar Ratios and Varying Curing Times Were Used in FEA to Predict the Modulus Value of Scaffolds that Could Be Made Using the Same Conditions

Tangent Modulus (MPa) (at 10\% Strain)

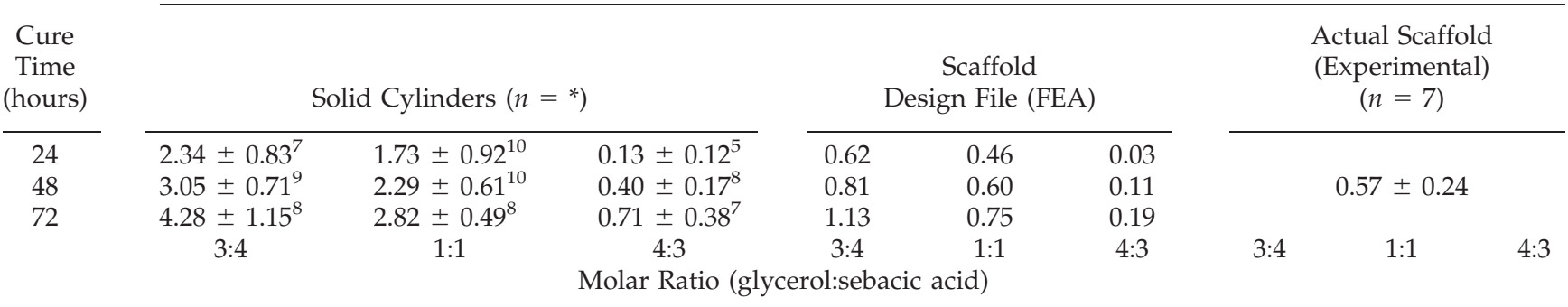

Scaffolds were tested experimentally to verify predictions.

*Sample size $(n)$ is displayed in superscript for each group. 

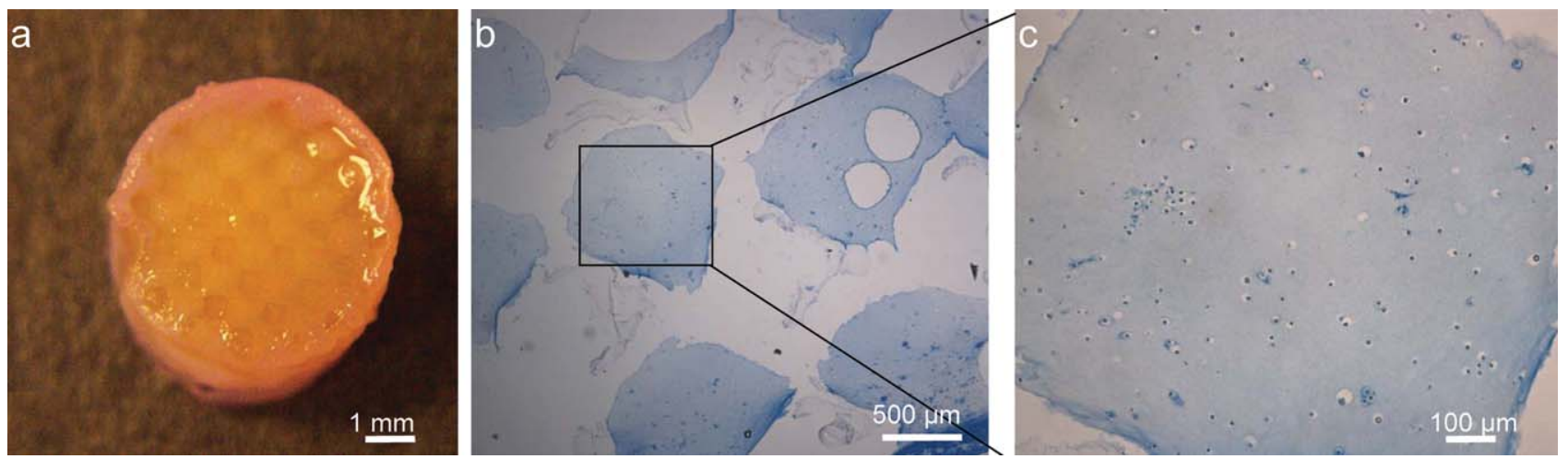

Figure 6. Digital images and histological sections (stained with alcian blue) show in vitro growth of cartilaginous tissue into PGS scaffolds. [Color figure can be viewed in the online issue, which is available at www.interscience.wiley.com.]

properties of a scaffold can be altered is through changing the structural features, such as pore size, porosity, interconnectivity, and pore shape. ${ }^{15,30}$ However, changing these features also has an effect on cartilage tissue regeneration. ${ }^{31-36}$ Working with a material whose intrinsic elastic properties can be altered enables fabrication of scaffolds with a wide range of architectures (designed for optimal tissue regeneration) from one material, all of which will support in vivo loads. PGS is beneficial in this respect, as its mechanical properties can be varied simply through changing the molar ratios of glycerol to sebacic acid during prepolymer synthesis or varying the duration of curing.

After establishing a collection of bulk mechanical properties for nine processing combinations (3 molar ratios $\times 3$ curing times), we used FEA to predict the elastic moduli of a 3D designed scaffold fabricated from these various batches of PGS. A single batch of scaffolds, fabricated from an intermediate of the nine processing combinations, verified that modulus values reported through FEA are reasonable estimates. This demonstrates the ability of image-based homogenization FEA to compute the effective tangent modulus of PGS scaffolds without the need for destructive testing.

Although PGS does not exhibit viscoelastic properties, the ability to match the elastic modulus of scaffolds to the equilibrium elastic properties of native cartilage is a step in the right direction, as this component is responsible for providing shape retention and strength. In comparison, a current clinical treatment, autologous chondrocyte implantation, has shown some success without any substantial mechanical support. ${ }^{37}$ However, patients must be extremely careful not to overload the delicate periosteal flap which envelopes the repair site. This draws a thin line between the amount of postoperative mechanical loading shown to enhance tissue regeneration, and the amount that will damage the graft. ${ }^{38}$ Incorporating a scaffold that matches the equilibrium elastic properties of native articular cartilage will allow for some degree of postoperative loading, a more robust environment to retain cell implantation, and temporary mechanical support that closely mimics the support provided by surrounding healthy tissue. Furthermore, this data can be applied to other soft tissue engineering applications that PGS is being studied for, such as myocardial tissue, ${ }^{7}$ where nonlinear elastic properties are highly desirable.

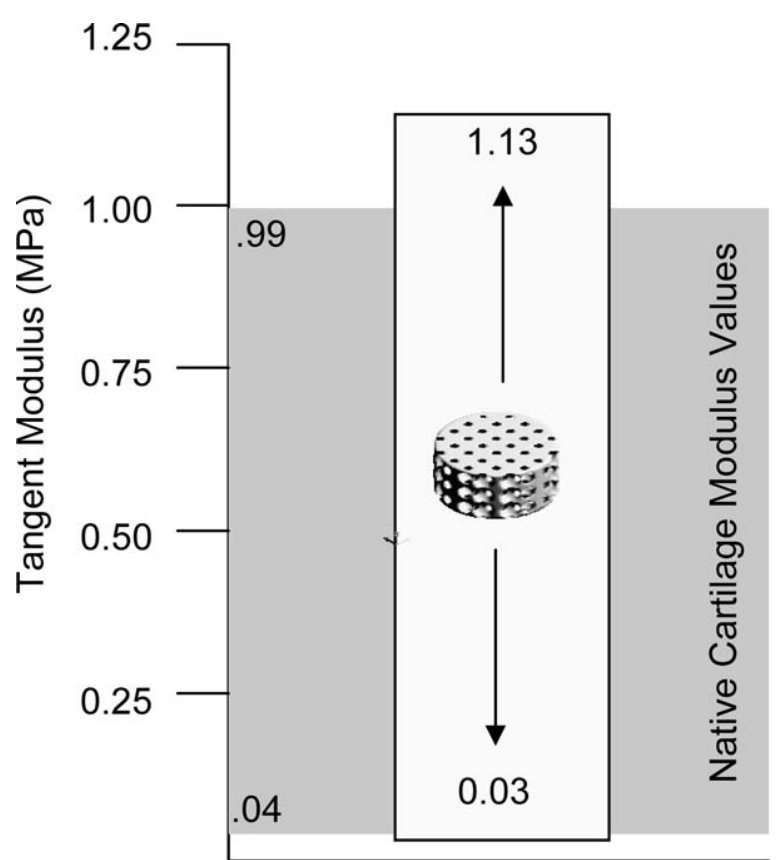

Figure 7. The FEA-predicted modulus values for this particular scaffold design fabricated from the collection of PGS bulk properties studied, range from 0.03 to $1.13 \mathrm{MPa}$, completely encompassing the native articular cartilage values that one might wish to match. 
The equilibrium elastic properties of experimental cartilage data can be separated out using the following equation:

$$
H_{\mathrm{A}}=\frac{E v}{(1+v)(1-2 v)}+\frac{2 E}{3(1-2 v)}
$$

where $H_{\mathrm{A}}$ is the aggregate modulus, $E$ is the equilibrium elastic component of this modulus, and $v$ is the Poisson's ratio. Poisson's ratio was assumed to be 0.3 , as experimentally measured by Cohen et al. ${ }^{39}$ With literature showing $H_{\mathrm{A}}$ values of healthy articular cartilage ranging from $0.089 \mathrm{MPa}$ to 2.22 $\mathrm{MPa}, 27,28,40-48$ the calculated equilibrium elastic component $(E)$ ranges from 0.04 to $0.99 \mathrm{MPa}$. As displayed in Figure 7, elastic modulus values predicted for this particular scaffold design from the collection of PGS bulk properties range from 0.03 to $1.13 \mathrm{MPa}$, completely encompassing the native tissue values that one might wish to match.

Furthermore, an in vitro experiment shows that PGS can indeed be used for cartilage tissue engineering applications where chondrocytes are seeded within a scaffold to produce a cartilaginous matrix. Aggrecan is expressed in higher levels on PGS scaffolds than in preseeded cells, showing favorable trends toward chondrogenesis. Collagen 2: collagen 1 ratio, commonly referred to as a "differentiation index" for chondrocytes, ${ }^{49}$ where a larger value represents more chondrogenic gene expression and a lower value represents more fibroblastic gene expression, is higher on PGS than on identical studies done using PCL. Differences between expression levels on PGS versus PCL may be related to the hydrophilicity of PGS which may enhance cell adhesion, retain more sGAG, and more closely mimic the native hydrophilic nature of cartilage ECM; however, further studies need to be done to verify this hypothesis.

PGS is a good candidate for cartilage tissue engineering applications. As shown for the first time, it can be fabricated into 3D-designed scaffolds using SFF techniques and is biocompatible with chondrocytes in vitro. Its bulk mechanical properties can be altered during synthesis and curing to match stiffness values of 3D-designed scaffolds to those of native cartilage. Furthermore, scaffold modulus values can be predicted using FEA, eliminating the need for destructive testing on custom scaffolds.

The authors thank Claire Jeong for fabricating many of the wax and HA molds used in this study.

\section{References}

1. Wang Y, Ameer GA, Sheppard BJ, Langer R. A tough biodegradable elastomer. Nat Biotechnol 2002;20:602-606.
2. Sundback CA, Shyu JY, Wang Y, Faquin WC, Langer RS, Vacanti JP, Hadlock TA. Biocompatibility analysis of poly (glycerol sebacate) as a nerve guide material. Biomaterials 2005;26:5454-5464.

3. Wang $Y$, Kim YM, Langer R. In vivo degradation characteristics of poly(glycerol sebacate). J Biomed Mater Res A 2003;66: 192-197.

4. Gao J, Crapo PM, Wang Y. Macroporous elastomeric scaffolds with extensive micropores for soft tissue engineering. Tissue Eng 2006;12:917-925.

5. Radisic M, Park H, Martens TP, Salazar-Lazaro JE, Geng W, Wang Y, Langer R, Freed LE, Vunjak-Novakovic G. Pre-treatment of synthetic elastomeric scaffolds by cardiac fibroblasts improves engineered heart tissue. J Biomed Mater Res A 2007;86:713-724.

6. Gao J, Ensley AE, Nerem RM, Wang Y. Poly(glycerol sebacate) supports the proliferation and phenotypic protein expression of primary baboon vascular cells. J Biomed Mater Res A 2007;83:1070-1075.

7. Chen QZ, Bismarck A, Hansen U, Junaid S, Tran MQ, Harding SE, Ali NN, Boccaccini AR. Characterisation of a soft elastomer poly-(glycerol sebacate) designed to match the mechanical properties of myocardial tissue. Biomaterials 2008;29:47-57.

8. Sales VL, Engelmayr GC Jr, Johnson JA Jr, Gao J, Wang Y, Sacks MS, Mayer JE Jr. Protein precoating of elastomeric tissue-engineering scaffolds increased cellularity, enhanced extracellular matrix protein production, and differentially regulated the phenotypes of circulating endothelial progenitor cells. Circulation 2007;116:I55-I63.

9. Fidkowski C, Kaazempur-Mofrad MR, Borenstein J, Vacanti JP, Langer R, Wang Y. Endothelialized microvasculature based on a biodegradable elastomer. Tissue Eng 2005;11:302309.

10. Motlagh D, Yang J, Lui KY, Webb AR, Ameer GA. Hemocompatibility evaluation of poly(glycerol-sebacate) in vitro for vascular tissue engineering. Biomaterials 2006;27:43154324.

11. Crapo PM, Gao J, Wang Y. Seamless tubular poly(glycerol sebacate) scaffolds: High-yield fabrication and potential applications. J Biomed Mater Res A 2007;86:354-363.

12. Nijst CL, Bruggeman JP, Karp JM, Ferreira L, Zumbuehl A, Bettinger CJ, Langer R. Synthesis and characterization of photocurable elastomers from poly(glycerol-co-sebacate). Biomacromolecules 2007;8:3067-3073.

13. Neeley WL, Redenti S, Klassen H, Tao S, Desai T, Young MJ, Langer R. A microfabricated scaffold for retinal progenitor cell grafting. Biomaterials 2008;29:418-426.

14. Chu TM, Hollister SJ, Halloran JW, Feinberg SE, Orton DG. Manufacturing and characterization of 3-d hydroxyapatite bone tissue engineering scaffolds. Ann N Y Acad Sci 2002; 961:114-117.

15. Hollister SJ. Porous scaffold design for tissue engineering. Nat Mater 2005;4:518-524.

16. Hollister SJ, Levy RA, Chu TM, Halloran JW, Feinberg SE. An image-based approach for designing and manufacturing craniofacial scaffolds. Int J Oral Maxillofac Surg 2000;29:6771.

17. Lin CY, Hsiao CC, Chen PQ, Hollister SJ. Interbody fusion cage design using integrated global layout and local microstructure topology optimization. Spine 2004;29:1747-1754.

18. Lin CY, Kikuchi N, Hollister SJ. A novel method for biomaterial scaffold internal architecture design to match bone elastic properties with desired porosity. J Biomech 2004;37:623-636.

19. Schek RM, Taboas JM, Hollister SJ, Krebsbach PH. Tissue engineering osteochondral implants for temporomandibular joint repair. Orthod Craniofac Res 2005;8:313-319. 
20. Schek RM, Taboas JM, Segvich SJ, Hollister SJ, Krebsbach PH. Engineered osteochondral grafts using biphasic composite solid free-form fabricated scaffolds. Tissue Eng 2004;10: 1376-1385.

21. Schek RM, Wilke EN, Hollister SJ, Krebsbach PH. Combined use of designed scaffolds and adenoviral gene therapy for skeletal tissue engineering. Biomaterials 2006;27:1160-1166.

22. Taboas JM, Maddox RD, Krebsbach PH, Hollister SJ. Indirect solid free form fabrication of local and global porous, biomimetic and composite 3D polymer-ceramic scaffolds. Biomaterials 2003;24:181-194.

23. Williams JM, Adewunmi A, Schek RM, Flanagan CL, Krebsbach PH, Feinberg SE, Hollister SJ, Das S. Bone tissue engineering using polycaprolactone scaffolds fabricated via selective laser sintering. Biomaterials 2005;26:4817-4827.

24. Kim K, Jeong CG, Hollister SJ. Non-invasive monitoring of tissue scaffold degradation using ultrasound elasticity imaging. Acta Biomater 2008;4:783-790.

25. Chu TM, Orton DG, Hollister SJ, Feinberg SE, Halloran JW. Mechanical and in vivo performance of hydroxyapatite implants with controlled architectures. Biomaterials 2002;23: 1283-1293.

26. Guilak F, Best BA, Ratcliffe A, Mow VC. Instrumentation for load and displacement controlled studies on soft connective tissues. AMD 1989;98:113-116.

27. Soltz MA, Ateshian GA. Experimental verification and theoretical prediction of cartilage interstitial fluid pressurization at an impermeable contact interface in confined compression. J Biomech 1998;31:927-934.

28. Ateshian GA, Warden WH, Kim JJ, Grelsamer RP, Mow VC. Finite deformation biphasic material properties of bovine articular cartilage from confined compression experiments. J Biomech 1997;30:1157-1164.

29. Farndale RW, Buttle DJ, Barrett AJ. Improved quantitation and discrimination of sulphated glycosaminoglycans by use of dimethylmethylene blue. Biochim Biophys Acta 1986;883: 173-177.

30. Hollister SJ, Lin CY. Computational design of tissue engineering scaffolds. Comput Methods Appl Mech Eng 2007;196: 2991-2998.

31. Miot S, Woodfield T, Daniels AU, Suetterlin R, Peterschmitt I, Heberer M, van Blitterswijk CA, Riesle J, Martin I. Effects of scaffold composition and architecture on human nasal chondrocyte redifferentiation and cartilaginous matrix deposition. Biomaterials 2005;26:2479-2489.

32. Freed LE, Marquis JC, Nohria A, Emmanual J, Mikos AG, Langer R. Neocartilage formation in vitro and in vivo using cells cultured on synthetic biodegradable polymers. J Biomed Mater Res 1993;27:11-23.

33. Malda J, Woodfield TB, van der Vloodt F, Wilson C, Martens DE, Tramper J, van Blitterswijk CA, Riesle J. The effect of PEGT/PBT scaffold architecture on the composition of tissue engineered cartilage. Biomaterials 2005;26:63-72.
34. Bhardwaj T, Pilliar RM, Grynpas MD, Kandel RA. Effect of material geometry on cartilagenous tissue formation in vitro. J Biomed Mater Res 2001;57:190-199.

35. Kuboki Y, Jin Q, Kikuchi M, Mamood J, Takita H. Geometry of artificial ECM: Sizes of pores controlling phenotype expression in BMP-induced osteogenesis and chondrogenesis. Connect Tissue Res 2002;43:529-534.

36. Griffon DJ, Sedighi MR, Schaeffer DV, Eurell JA, Johnson AL. Chitosan scaffolds: Interconnective pore size and cartilage engineering. Acta Biomater 2006;2:313-320.

37. Peterson L, Minas T, Brittberg M, Nilsson A, Sjogren-Jansson E, Lindahl A. Two- to 9-year outcome after autologous chondrocyte transplantation of the knee. Clin Orthop Relat Res 2000;374:212-234.

38. Lewis PB, McCarty LP III, Kang RW, Cole BJ. Basic science and treatment options for articular cartilage injuries. J Orthop Sports Phys Ther 2006;36:717-727.

39. Cohen B, Lai WM, Mow VC. A transversely isotropic biphasic model for unconfined compression of growth plate and chondroepiphysis. J Biomech Eng 1998;120:491-496.

40. Williamson AK, Chen AC, Sah RL. Compressive properties and function-composition relationships of developing bovine articular cartilage. J Orthop Res 2001;19:1113-1121.

41. Klein TJ, Chaudhry M, Bae WC, Sah RL. Depth-dependent biomechanical and biochemical properties of fetal, newborn, and tissue-engineered articular cartilage. J Biomech 2005;40: 182-190.

42. Bursac PM, Obitz TW, Eisenberg SR, Stamenovic D. Confined and unconfined stress relaxation of cartilage: Appropriateness of a transversely isotropic analysis. J Biomech 1999;32:11251130.

43. Soltz MA, Ateshian GA. Interstitial fluid pressurization during confined compression cyclical loading of articular cartilage. Ann Biomed Eng 2000;28:150-159.

44. Moroni L, de Wijn JR, van Blitterswijk CA. 3D fiber-deposited scaffolds for tissue engineering: Influence of pores geometry and architecture on dynamic mechanical properties. Biomaterials 2005;27:974-985.

45. Schinagl RM, Gurskis D, Chen AC, Sah RL. Depth-dependent confined compression modulus of full-thickness bovine articular cartilage. J Orthop Res 1997;15:499-506.

46. Schwartz CJ, Bahadur S. Investigation of articular cartilage and counterface compliance in multi-directional sliding as in orthopedic implants. Wear 2007;262:1315-1320.

47. Armstrong CG, Mow VC. Variations in the intrinsic mechanical properties of human articular cartilage with age, degeneration, and water content. J Bone Joint Surg Am 1982;64:88-94.

48. Athanasiou KA, Agarwal A, Dzida FJ. Comparative study of the intrinsic mechanical properties of the human acetabular and femoral head cartilage. J Orthop Res 1994;12:340-349.

49. Martin I, Jakob M, Schafer D, Dick W, Spagnoli G, Heberer M. Quantitative analysis of gene expression in human articular cartilage from normal and osteoarthritic joints. Osteoarthritis Cartilage 2001;9:112-118. 